\title{
Sustainable Development of Industrial Enterprises in Crisis
}

Tatiana Alferova

Perm Institute of Economics and Finance, Perm, Russia,

Vlasova St.15, apt.93, Perm, Russia, 614065

Ekaterina Ponosova

Perm Institute of Economics and Finance, Perm, Russia,

Vlasova St.15, apt.93, Perm, Russia, 614065

atw-36@rambler.ru

\section{Doi:10.5901/mjss.2015.v6n3s6p27}

\begin{abstract}
This article presents the questions of sustainable development of industrial enterprises through the prism of sustainable and unsustainable development identification. Based on statements of the theory of economic systems we define conditions enabling industrial systems to develop steadily, give the factors affecting the sustainable development of industrial enterprises.
\end{abstract}

Keywords: sustainable development, crisis management, stability, management factors, industrial system

\section{Introduction}

Modern society can justly be considered as a consumer society where economic growth and economic activity long have been a focus of attention. Goods are becoming cheaper, more goods are produced, they are transported from one part of the world to another, becoming available to more people. World GDP has increased from about $\$ 16$ trillion to over40 trillion dollars since the mid 1970s to the present time (OECD Insights, 2008). Thus only $3.2 \%$ of used natural energy is consumed, and the rest becomes waste, which nature is unable to process (Borodin, 2010). Trends in global production and consumption are unlikely to change significantly in the near future, but resource-based approach to the interaction of man and nature inevitably leads to its damage, besides nature already partially lost the ability to heal itself in its former capacity (in status quo).

Serious short comings in the existing mechanisms of global development most clearly identified food, energy, financial and climate crises that began to develop at the same time at the end of the first decade of the XXI century. In this connection the problem of sustainable development is becoming especially important considering limited resources and the inability to further economic growth due to extensive factors.

\section{Methods and Materials}

To ensure social, economic and environmental stability it is important to implement major reforms in mechanisms of the world economy governance and to develop a new paradigm of development, one of the aspects of which should be a focus on ensuring sustainable development that involves a balanced combination of tangible wealth development activity, protection of the environment and providing social equity and justice (Alferova \& Tretiakova, 2013).

Industrial enterprises which play an extremely important role in the socio-economic prosperity of any country should fully participate in implementation and evaluation of institutional reforms related to sustainable development. The use of more efficient production processes, the implementation of preventive strategies, employment of clean production technologies and procedures throughout product lifecycle will result in no waste or minimizing their volume, which will play an important role in mitigating the impact of resource use and preservation of the environment (Alferova, 2012). In these circumstances, the most critical task is to transform industrial enterprises management principles with identification of the most important factors contributing to their sustainable development.

Distinction between the concepts of economic development and growth is highly important in identification of sustainable and unsustainable development. From the concept of sustainable development, economic indicators growth also has a mixed assessment, as it may indicate intensification of exploitation of natural resources, the destruction of 
natural life-support systems.

\section{Results}

Sustainable development of industry corresponds to the growth on the latest technology - economical growth. Unsustainable development corresponds to the growth with significant resources. Extensive development requiring environmental resources based on backward technologies, leading to exhaustion of natural resources, environmental degradation, underdevelopment and poverty, refers to unsustainable development type.

A prerequisite for the development is resistance to the constant renewal and self-improvement, changing conditions and purposes of industrial system operation. This means that structure of industry should be flexible, adaptive, changeable tin order to overcome the imbalance of elements. Structural reforms in the framework of sustainably developing system take a form of modernization as a process of continuously improving changes. The absence of significant structural changes within the unsustainable development can realize its downward option (regression, degradation), conservation (stagnation) of the old structure. The birth of a new system (structural shift) occurs through the collapse of the old one. As a result of a structural shift, a new system, more organized, structured, well-balanced than the previous one, resolved its contradictions or brought in balance with the existing restrictions (Ponosova, 2012).

Thus, systems constantly being upgraded get sustainable development as the unstable is what does not develop.

In the scientific literature there is a large range of opinions and assumptions about the fundamental principles of sustainable development. J. Kazieva (2009) noted that the basis for the formation of the state strategy of sustainable development should be based on the following principles:

1) the unity of man and nature. Humanity is a part of the living world, the biosphere and can only exist while maintaining a certain level of ecological balance;

2) the interaction between man and nature and the decisive role belongs to the labor process. In other words, not a "zero" economic growth and economic management restrictions but work improvement can prevent biological adaptation of a man and general ecological disbalance;

3) the economy is a part of ecosystem. This means that the production of goods must be conformed to environmental laws, it is necessary to build a qualitatively new environmentally sound economic model where business processes perfectly fit in the biosphere cycles;

4) the principle of equilibrium use of nature, meaning the balance of consumption and reproduction of natural resources;

5) the principle of social justice, involving the eradication of poverty, ensuring a more equitable distribution of income, human resource development, quality of life, equality in the use of global natural resource potential, distributive justice of natural wealth between generations;

6) the co-evolution principle as the idea of preserving a man and the biosphere.

Based on the provisions theory of economic systems and other sources, the author (Kazieva, 2009) concludes that the industrial system develops stable if:

1) it long retains its existence (objective economic laws are not violated, especially the law when the level of production relations development is related to the level of productive forces development);

2) it adapts to environmental changes by changing its own structure (has a flexible structure);

3) it effectively counteracts the perturbing effects of external and internal environment (secures development);

4) it has a potential for self-development;

5) it does not destroy the natural basis of its existence (i.e. it is environmentally friendly).

Thereunder, factors of industrial sustainable development are divided into groups (Kazieva, 2009):

1) structural;

2) productive forces;

3) productive relations;

4) factors of safety;

5) environmental;

6) factors of self-development potential.

The factors above are distinguished from the variety of factors influencing sustainable development, based on the following considerations:

1) Sustainable development of the structure is necessary to preserve the system integrity;

2) synchronous development of productive forces and productive relations expresses the most important relationship for the economic system; 
3) security and preservation of natural systems - the imperatives of the time;

4) capacity development is a source of system self-development.

These factors corresponds to the objectives of national economy from the standpoint of sustainable development, namely the continuity of economic development, the safety of citizens and the state, solving environmental and social problems.

Factors of sustainable industrial development can be taken as a basis for the base structure of industrial enterprise management factors.

Agreeing basically with the approach outlined in the work of J. Kazieva, we believe necessary to note that in the global and domestic practice approaches were already developed, adopted and approved by the international community in general and in corporate sector in particular. These approaches allow allocation of the basic elements of the structure of industrial enterprise management factors in the present context.

These approaches are reflected in the Guidance on sustainable development reporting developed by the Global Reporting Initiative (GRI). In particular, in the guidelines (Guidance on public reporting for small and medium enterprises, 2003; Guidance on sustainable development reporting, 2006) you can see four blocks of open reporting on sustainable development, which can be transformed as a structure of industrial enterprise management factors on the modern stage. Namely:

1. General Information:

- The position of management in relation to the purposes of publication;

- Basic principles of company management system;

- Existing management and policy systems;

- Content (subjects and covered objects / activities) of reports;

- The approaches and methods of public reporting, including frequency of the publication of materials, contact information for feedback.

2. The economic block:

- The nature of economic activities;

- The distribution by the markets;

- Major partners;

- Changes in volume and nature of production;

- The most significant investment projects and contracts;

- The contribution of wages, raw materials and energy resources in cost;

- The cost of training and other forms of investment in human resources;

- $\quad$ Amounts paid in taxes and spent on charity;

3. The social block:

- Information on production safety, injuries;

- Working conditions;

- Providing the health of personnel, the incidence;

- Creation of jobs;

- Information about salaries and bonuses, social benefits;

- Staff turnover and staff resources;

- Informing and training staff;

- Informing the consumer about the product and labeling;

- Patronage over social and cultural facilities and sponsorship;

4. Environmental block:

- The characteristics of the impact of production process, products and services on air, water bodies, soil, flora and fauna, human health;

- Emergency and outside impact;

- Energy consumption and energy;

- Consumption of resources;

- The possibility of reuse or recycling of products;

- Efforts to reduce and prevent exposure;

- Working with partners in order to reduce the impact on the environment;

- Voluntary activities for protection and recovery of natural, cultural and historical sites.

We would like to note that the "General Information" block describes the institutional features of enterprise.

The requirements of Town Planning Code, adopted in 2005, methodologically extend this approach. In this 
approach the requirement to provide a balanced accounting of the environmental, economic, social and other factors is determined for sustainable development of territorial entities and enterprises including city-like in one sense or another.

\section{Conclusion}

In conclusion, we can say that the basic structure of industrial enterprise management factors now from the point of sustainable development is a balanced combination of social, economic, environmental, institutional and technological factors. And we propose to base the determination of the industrial enterprise management factors in the current economic crisis on the paradigm of the theory and methodology of management, including the following areas of management factors formation: politics, economics, cybernetics, informatics (information theory), ACS (automatic control theory), philosophy (philosophy of enterprise), law, sociology (social system balance), the environment (sustainable development), psychology, logic (logistics), rhetoric and ethics.

\section{References}

Alferova T. (2012). The institutionalization of sustainable development of industrial enterprises // Herald of the University of Perm. Series «Economics». №4 (15). P.28-33.

Alferova T., Tretiakova E. (2013). Sustainable development of socio-economic systems: theoretical aspects / Ekaterinburg: Institute of economics UB of RAS. P.186.

Borodin A. (2010). Formation of sustainable development of regional system based on economic-ecological programming: author's abstract. Kaliningrad. P.3.

Guidance on public reporting for small and medium enterprises. (2003). M.: Ecoline.

Guidance on sustainable development reporting. (2006). GRI, version 3.0, 2000-2006. M.:Ecoline.

Kazieva J. (2009). Sustainable development of industry (theory and methodology). author's abstract. Makhachkala.

OECD Insights - Sustainable Development: Linking Economy, Society, Environment. (2008). ISBN 978-92-64-055742 ๑ OECD - P.7.

Ponosova E. (2012). Fundamentals of factor model of industrial enterprises crisis management. - Yekaterinburg: Federal State Institution of Science Institute of Economics, Ural Branch of the Russian Academy of Sciences. P.171. 